\title{
Spectral Splitting Luminescent Solar Concentrator Panels for Agrivoltaic Applications
}

\author{
Quinn Daigle, Nima Talebzadeh, Ijaz A. Rauf, Paul G. O'Brien \\ Department of Mechanical Engineering, Lassonde School of Engineering, York University \\ 4700 Keele Street, Toronto, Ontario, M3J 1P3, Canada \\ Quinn.Daigle@gmail.com; Paul.obrien@lassonde.yorku.ca
}

\section{Extended Abstract}

A diverse range of sustainable energy sources will play a crucial role in building a sustainable future and reducing greenhouse gas emissions. There is an increase in competition between food and energy production for land use and as such, interest in co-use of land for both agricultural and energy production has become an area of interest for research [1]. Multiple studies have been conducted that analyse various approaches for using silicon solar panels on greenhouse roofs and the effects on crop yields, energy production and microclimate. [2] [3] [4] [5]

This study investigates the concept of using semi-transparent luminescent solar concentrators as greenhouse rooftop panels for the co-production of food and energy. Both the crops and luminescent dyes used in solar concentrators have a specific absorption spectrum for solar radiation. [6] Plants have a high absorption of light in the blue and red spectrum with peaks at $440 \mathrm{~nm}, 620 \mathrm{~nm}$, and $670 \mathrm{~nm}$ [7] which it uses for photo morphological/phototropic responses and photosynthesis, respectively [8]. A luminescent concentrator that allows light of these wavelengths to pass undisrupted through while capturing energy for electrical conversion from other areas of the spectrum offers a promising solution to agrivoltaic applications.

Photosynthetically active radiation (PAR) consists of solar radiation from between 400-700 nm which is used by crops to drive photosynthesis. Non-PAR, or non-photosynthetically active radiation, is light that falls outside these wavelengths such as infrared and UV radiation which can be captured and converted into electricity without impacting the photosynthetic rate of the crops. Luminescent dyes that absorb light in the PAR region and the IR region are integrated into the model. By carefully choosing a luminescent dye that absorbs radiation from the non-PAR spectral region and from the regions of low photosynthetic absorption in the PAR region, electricity can be generated while minimizing the effects of reduced solar irradiance on crop yield.

By reducing the amount of light entering the greenhouse the crop experiences a shading effect and the micro-climate within the greenhouse is altered. Shading on greenhouses is commonly used in warm climates during summer [9] [10] [11]. An analysis of the literature on the effects of shading in greenhouses was done to assess the possible impacts of semitransparent roof material on the microclimates and crop yields in greenhouses. A reduction of solar radiation due to greenhouse shading was found to have a beneficial effect on crop yield and water use in climates/seasons with high solar irradiance and hot temperatures [3] [9] [10] [11].

Herein we perform numerical analysis to model a greenhouse made using semi-transparent roof-top panels that function as luminescent solar concentrators that direct non-PAR onto photovoltaic cells located at the edges of the panels. Our results show that by designing LSCs with optimal concentrations and types of dye the operation of a greenhouse can be greatly enhanced in terms of thermal management, crop production, electric power production and profit.

\section{References}

[1] B. A. Keating, M. Herrero, P. S. Carberry, J. Gardner and M. B. Cole, "Food Wedges: Framing the Global Food Demand and Supply Challenge Towards 2050," Global Food Security, vol. 3, no. 3-4, pp. 125-132, 2014. 
[2] M. Cossu, L. Murgia, L. Ledda, P. A. Deligios, A. Sirigu, F. Chessa and A. Pazzona, "Solar Radiation Distribution inside a greenhouse with south-oriented Photovoltaic roofs and effects on crop productivity," Elsevier, vol. 133, pp. 89-100, 2014.

[3] R. Hassanien, E. Hassanien and L. Ming, "Influence of grenhouse-integrated semi-transparent photovoltaics on microclimate and lettuce growth," International Journal of Agricultural and Biological Engineering, vol. 10, no. 6, pp. 11-22, 2017.

[4] K. Ezzaeri, H. Fatnassi, R. Bouharroud, L. Gourdo, A. Bazgaou, A. Wifaya, H. Demrati, A. Bekkaoui, A. Aharoune, C. Poncet and L. Bouirden, "The Effect of Photovoltaic panels on the microclimate and on the tomato production under photovoltaic canarian greenhouses," Solar Energy, vol. 173, pp. 1126-1134, 2018.

[5] M. Cossu, A. Yano, L. Murgia, L. Ledda, P. A. Deligios, A. Sirigu, F. Chessa and A. Pazzona, "Effects of the PhotoVoltaic Roofs on the Greenhouse Microclimate," Acta Horticulture, pp. 461-468, 2017.

[6] L. R. Wilson, "Luminescent Solar Concentrators: A Study of Optical Properties, Re-absorption and Device Optimisation," 2010.

[7] K. McCree, "The Action Spectrum, Absorptance and Quantum Yield of PhotoSynthesis in Crop Plants," Agricultural Meteorology, vol. 9, pp. 191-216, 1970.

[8] N. Roslan, M. Ya'acob, M. Radzi, Y. Hashimoto, D. Jamaludin and G. Chen, "Dye Sensitized Solar Cell (DSSC) greenhouse shading: New Insights for Solar Radiation Manipulation," Renewable and Sustainable Energy Reviews, vol. 92, pp. 171-186, 2018.

[9] H. M. Cathey, "Energy-Efficient Crop Production in Greenhouses," in ASHRAE Transactions, Denver, 1980.

[10] N. Radojevic, D. Kostadinovic, H. Vlajkovic and E. Veg, "Microclimate control in greenhouses," FME Transactions, vol. 42, no. 2, p. 171, 2014.

[11] A. Baille, C. Kittas and N. Katsoulas, "Influence of Whitening on Greenhouse Microclimate and Crop Energy Partitioning," Elsevier, vol. 107, pp. 293-306, 2001.

[12] H. M. Cathey, "Energy-Efficient Crop Production In Greenhouses," ASHRAE, vols. DV-80-2, no. 4. 